\title{
Analysis of the Characteristics of Stone Signposts in Korean Rural Landscapes
}

\author{
Young-Chang Lee ${ }^{1}$, Hae-Joon Jung ${ }^{2}$ and Keun-Ho Kim ${ }^{3, *}$ \\ 1 Institute of Environment and Ecology, O-Jeong Eco Resilience Institute (OJERI), Korea University, \\ Seoul 02841, Korea; envi0320@gmail.com \\ 2 Department of Landscape Architecture, College of Engineering, Keimyung University, \\ 1095 Dalgubeol-daero, Daegu 42601, Korea; hj.jung@kmu.ac.kr \\ 3 Department of Forest Resources and Landscape Architecture, College of Life and Applied Sciences, \\ Yeungnam University, 280 Daehak-Ro, Gyeongsan, Gyeongbuk 38541, Korea \\ * Correspondence: manchester99@ynu.ac.kr
}

Received: 4 July 2018; Accepted: 24 August 2018; Published: 3 September 2018

\begin{abstract}
Korean rural landscapes have been influenced by major events in modern Korean history, and have undergone many sociocultural and lifestyle changes. This study examines the characteristics of stone signposts, which physically represent the landscape entrance to Korean rural villages, and provide comprehensive information for the sustainable management of rural landscape elements having heritage value. We conducted field surveys and interviews in 313 rural villages in Korea and cross-tabulated the collected data with five question items. We designed one descriptive variable for the cause, set four question items for dependent variables, and analyzed the relationship among the variables. This study reveals that the installation times of stone signposts are related to the major issues of modern Korean history, and discusses how the signposts evolved into rural landscape elements. In addition, the study reveals that stone signposts can be considered a tactic designed to preserve regional identities in modern society and improve the quality of rural village landscapes. Over time, due to the complex long-term interactions that occurred between the landscape and the sociocultural environment of such regions, stone signposts evolved into elements of cultural heritage and representations of regional knowledge and history. Therefore, in order to improve Korean rural landscapes, their value must be assessed and managed independently based on historical, regional, and landscape considerations.
\end{abstract}

Keywords: rural landscape; stone signpost; sustainable heritage management

\section{Introduction}

\subsection{Research Background}

Rural landscapes are the result of interactions between natural and anthropogenic environments, as well as between the past and present [1]. Traditional rural landscapes, in this regard, have received global attention due to their holistic and complex characteristics that maintain bio-cultural diversity, which is considered a key element in achieving sustainable development [2,3]. Ample empirical evidence indicates that rural landscapes support a wide array of species; have a large range of functions for the human population; and contribute to social, economic, and environmental sustainability in multiple ways [4-6]. They evolve continuously as a result of a combination of various factors, such as community values, social systems, customs, and humankind's longstanding agrarian lifestyle, which have enabled the sustainable use of an extensive range of ecosystem services and social systems by future generations $[7,8]$. Such long-term and complex interactions between sociocultural and 
landscape factors have created a sense of embeddedness and identity within the community living in a landscape [3,9].

To safeguard these valuable rural landscapes, many countries have currently implemented bureaucratic approaches within a heritage context. Cultural heritage has generally been regarded as a "conveniently ambiguous" concept $[10,11]$. However, government-led efforts prioritize the physical intactness of entire or the "outstanding" landscapes without completely understanding how people living in the landscape imbue landscape features with pluralistic meanings and human values in their everyday lives. Moreover, these academic and bureaucratic approaches in a heritage context have been heavily weighted in conserving monumental architecture, archaeological discovery, and their vicinity areas, which clearly show the life of a certain period and constitute a strong cultural identity of a nation. Even though the matter of cultural heritage is a historic project, the decision-making process, including which asset should be conserved, restored, or changed, should be closely connected to the modern concerns. For example, this ought to include the question of whether heritage assets inform people about the nature of society, contribute toward social stability and cohesion in the community, or present ways for the peaceful coexistence with nature [10]. This present-centered discourse highlights the idea that cultural heritage is often judged as a type of collective memory: a social product shaped by the economic, political, and social concerns of the present $[12,13]$. In this context, heritage is not just an "outstanding thing"; rather, it has material consequences, and represents a set of attitudes to and relationships with the past [14-16]. Co-produced and molded as a result of the relationship between people and their surrounding visible and invisible environments, these relationships are identified by an attachment and veneration to objects, places, and practices that have been regarded as a way to bridge or manifest the past in some way $[17,18]$. Therefore, cultural heritage might be interpreted according to the demands of the present, while reflecting current concerns about the past, which, in turn, could be sustained for future generations $[19,20]$. In this regard, heritage discourses and projects, have progressed based on a selective interpretation of the evidence that addresses modern concerns, especially when it involves environmental design that features some artifacts while transforming, sacrificing, or ignoring others [21]. However, in the present, the landscape features of rural areas have long been out of the heritage discourses. Even though most modern landscape features were erected by the top-down government-led projects designed by a few and specific experts, they are also the traces of the era left in the living place by the people as a result of them accepting or adapting to their changing social, economic and cultural environments. In other words, while coexisting and communicating with people, and characterizing the present-day rural landscapes, landscape features in the present also can be a "living" cultural heritage; people, events, and aspects of life can be connected through a landscape to the present $[22,23]$. However, the discussion of the value and sustainability of these extended heritage concepts is largely concentrated in the urban or outstanding places. Therefore, it is necessary to study how these rural landscape features have determined the insiders and outsiders' perception on the traditional rural landscape, and whether these features have intrinsic values as a cultural heritage.

In recent years, Korea's unique rural landscapes have rapidly undergone many sociocultural and lifestyle changes; such changes include demographic changes, land abandonment, agricultural intensification, pressures exerted by urban development, the loss of traditional and local knowledge, and climate change [24-27]. According to researchers, these landscape changes comprise a threat or negative evolution because they have significantly reduced the diversity and identity of cultural landscapes and resulted in a diminished sense of place $[2,28,29]$. Meanwhile, various government-led studies and projects have examined rural landscapes based on the rural regional plans that were prepared after the government's policy shifted toward rural environment development in the late 1990s [30]. However, although almost all such government-led comprehensive regional development plans thoroughly examine regional resources, very few studies or plans investigate how the characteristic Korean rural landscapes are created, or the residents interact with their surroundings. In general, studies on Korean rural landscapes focus on the spatial characteristics of traditional rural 
villages [31-37] or traditional community facilities, such as village halls, golden age clubs, commune shelters, playgrounds, collective warehouses, and storage facilities [38-40]. However, these studies do not identify the tangible and intangible values of rural landscape features during the industrialization period. This holds especially true for the stone signpost, as one of the most dominant landscape features that has important spatial and temporal implications of this feature due to its location at the village entrance, which is a very significant place in terms of defining a village's characteristics and identifying the community spirit [30].

\subsection{Research Aim}

Typically, Korean villages are built on the southern side of hills to ensure that winter sunlight is not lost. They are placed well above the flood level and have wide fields that are crossed by streams, a low hill toward the south, sheltering spurs toward the east and west, and curving approach roads to block intruders [32,41]. Usually, the village entrance, where most of the stone signposts are located, is formed around a watershed that is important to the daily lives of inhabitants. This place is located between the approaching road that connects the village to the outside world and the internal road leading to the village center. It is a significant communal place that serves as a node, which interconnects the bottom house and village outside, as well as the top (on the hill at the back), middle (a residential space), and bottom (arable land and gardens) houses [30]. The space around the village entrance marks the first gateway where villagers and visitors encounter village territory [32]. In this respect, this space plays a crucial role in creating a visitor's first impression of the village. Due to these reasons, the village entrance has long been considered an important geomantic factor with symbolic meanings [42]. Symbolic landscape features, such as a jangseung (a tutelary post), a sotdae (a pillar representing the village guardian), altars, shrines, and human-made groves, where rituals were offered for the continued health and prosperity of the village, were created [43]. In contrast, stone signposts started being erected at village entrances from the early 1970s onward, which was a time marked by the advent of industrialization in Korea. These small structures are carved with the villages' names and history; they were once a totem pole representing the village's prosperity to their guardians, and are now merely a landscape feature of Korean rural villages. Only a few studies have examined these stone signposts in detail, despite the value of these features as a key physical element of the Korean rural landscape. It is necessary to understand the physical characteristics of stone signposts, as well as their spatial and temporal implications for Korean rural landscapes, which have evolved through the process of adaptation of the landscapes' inhabitants to the rapid transitions toward modernity that occurred from the 1970s onward. By understanding these interactions based around the stone signposts, this study aims to obtain information on the value of the signposts as rural landscape elements in order to ensure their sustainable conservation and management as cultural heritage.

\subsection{Traditional Landscape Management of Stonework}

In general, agricultural societies in Korea have always emphasized fecundity and abundance in their worship of nature: they believe that life is not possible unless the principles of nature are respected [44]. To choose and support livable, auspicious settlements that are in harmony with nature, the methods of Bibo Feng-shui, which are believed to have been introduced by the Zen master Doseon in the ninth century, are extensively used as an adaptation strategy for living in the Korean Peninsula [45].

The Feng-shui theory, or traditional geomancy, is closely related to the cultural aspects of landscape change and management practices, reflecting East Asian perspectives of nature and organic cosmology. It has immensely affected landscape cultures. The Feng-shui theory comprises a set of empirical rules, integrating biophysical landscape components with cultural traditions and religious beliefs that guide the practice of selecting and designing homes and burial places [46,47]. Even today, Korean culture is much influenced by Feng-shui. Although the theory is considered mystical, it is a way of harmonizing human existence with the surrounding environment in practice [48]. Bibo renders 
a site auspicious by making up for the site's missing elements and reducing its strong elements through artificial means. In other words, if the flow of chi (vital force or energy) through a selected site is too weak or too strong, or the site's spatial arrangement and structural layout is not sufficiently auspicious, we can alter landscape features around the site in conformance with the Feng-shui theory [49].

When selecting and managing places to live, the Feng-shui theory focuses on the management of Sugu, the mouth of the watercourse where water flows in and out. Sugu is usually co-located with the entrance to a village because that area is considered an important geomantic place with symbolic meanings [42]. If the geographical conditions of a Sugu in the selected place are open or wide, it must be blocked and protected with artificial woodlands, ponds, or mounds in order to maintain chi to ensure the prosperity of the village [50]. In addition to modifying landscape features, villagers erect symbolic structures made of stones at the Sugu or village entrance to compensate for areas that are physically or psychologically deficient.

Traditionally, in some rural village rituals, stones have been venerated as the embodiment of deities because of the former's solidity and durability. Usually, such stones are unnaturally round, erect, or oversized and shaped similar to a jangseung, sotdae, stone grave, altar, or shrine. These features enable them to overcome their deficiencies and achieve balance and harmony between buildings and their natural surroundings. Therefore, stoneworks in Sugu areas are believed to be endowed with various powers, such as the ability to reinforce the Earth's energy (or chi), which influences the village's prosperity, peace, and destiny [51]. However, from the 1970s onward, simple, standardized stone signposts started replacing the traditional stonework at village entrances. This was the result of the government-led modernization movement for agricultural societies, which was called the Saemaul Undong Movement or the New Community Movement [52]. In recent years, with the advancement of rural and green tourism as a strategy to increase rural household incomes, the number of stone signposts (in various styles and forms) has been increasing. Residents understand that these signposts help promote a distinctive image of the village and its characteristics to the outside world [53]. However, some argue that the current vertical pattern aims to enhance visibility alone, and the excessive scales of stylobates, hoop monuments, and explicit manufacturing patterns do not fit the rural landscape. In order to resolve this problem, comprehensive information on the topic is urgently required and, today, it is necessary to adopt new policies to increase the sustainability of rural village landscapes. It is noted that the protection and enhancement of rural landscapes have environmental, social, and economic significance.

The remainder of this study is organized as follows. Section 2 describes the manner in which we collected stone signpost data for our study areas. Section 3 depicts the results of survey question items and analyzes these results to reveal their relationships. The major results of the study are discussed in Section 4. Finally, Section 5 presents the conclusions and future directions of the study.

\section{Materials and Methods}

\subsection{Study Area}

The study area, Jeollanam-do, is a province located in the southwestern part of the Republic of Korea (Figure 1a). It is located in the center of Northeast Asia, is a cardinal point on the Eurasian continent, and lies between China toward the west and Japan toward the southeast; further, it is a portal into the Pacific Ocean. Three rivers, the Youngsan River, which flows into the Mokpo Gulf; Sumjin River, which originates in Chonbuk and flows into the eastern mountains of Chon-nam-buk; and Tamjin River, which runs through the Jangheung Gun and Gangjin Gun river valleys, enter Jeollanam-do and form vast southwestern and northwestern plains in their valleys, providing fertile farmlands. The Naju Plain in the Youngsan River valley, together with the Homan Plain in Chonbuk, forms Korea's breadbasket. The study site was developed as an agricultural region. The study involved 313 rural villages in Damyang-gun, which included the following sampling sites: 23 in Subuk-myeon; 27 in Daejeon-myeon; 23 in Gokseong-gun, Okgwa-myeon; 22 in Gyeom-myeon; 23 in Osan-myeon; 37 in 
Boseong-gun, Deungnyang-myeon; 23 in Hoecheon-myeon; 15 in Ungchi-myeon; 47 in Suncheon-si, Seo-myeon; 52 in Hwangjeon-myeon; and 21 in Woldeung-myeon (Figure 1b). The broad characteristics of these studied villages are based on a land usage system that divides the land into several categories, such as residential areas, surrounding areas, and land under cultivation [54].

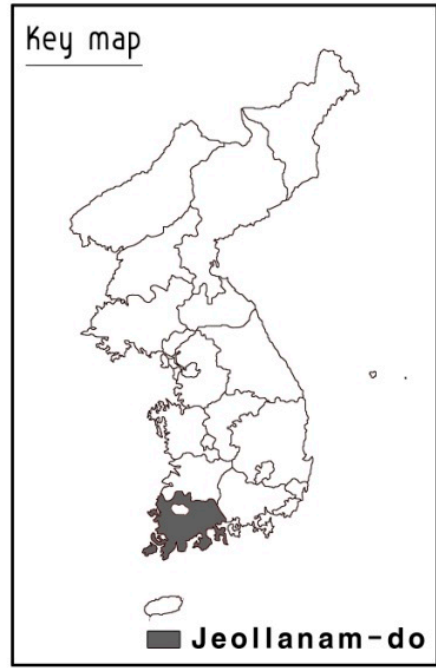

(a)

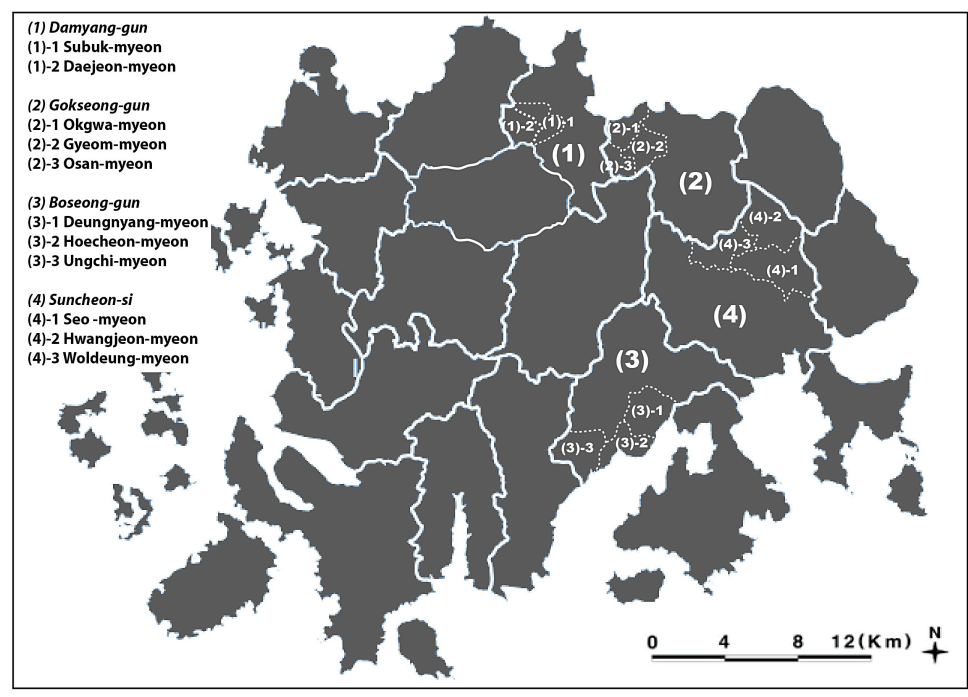

(b)

Figure 1. Location of: (a) Study area in Korea; (b) Sampling regions within the study area.

\subsection{Methods}

To identify the key characteristics of the stone signposts installed in Jeollanam-do's rural villages, a field survey was conducted from August to September 2016. First, specialized researchers who had received preliminary training on survey contents, survey methods, and interview surveys participated in the field surveys. Besides one rural resident who was recommended by the municipal body of each village, the specialized researchers consisted of two graduate students and two volunteers of civic groups, all four of whom were regular members. For a field survey administered to 313 rural villages, these specialized researchers received survey responses from 244 residents of 244 rural villages, which consisted of 100 in Suncheon-si, 53 in Boseong-gun, 59 in Gokseong-gun, and 32 in Damyang-gun. However, no field investigations were conducted in the 69 rural villages that had no stone signposts. Table 1 provides the list of items and the respective response options in the field surveys. In addition to choosing the response in the questionnaire, interviews with rural residents were conducted for the items "(2) Time of installation" and "(3) Creators of stone signposts". The items "(1) Existence of stone signposts" and "(4) Characteristics of appearance stone signposts" present multiple options regarding the existence and appearance of stone signposts. Finally, the item "(5) Discernment of stone signpost" offers choices for the direct evaluation of the stone signposts by the rural residents. Data on items such as "Time of installation" and "Creators of stone signposts" were collected by interviewing people such as local residents and government officials. Through the direct interview survey, we could confirm the times of erection and the creators of all the signposts. Especially, through the responses to the items concerning the existence and appearance (items 1 and 4) of 244 stone signposts, the researchers also collected data regarding "existence of stone signposts" and "characteristics of appearance stone signposts". However, for the item "Discernment of stone signpost", the specialized researchers received a first-hand account of the discovery of the stone signposts in 244 rural villages from the local residents. 
Table 1. List of items and options used for field surveys in rural villages.

\begin{tabular}{|c|c|c|}
\hline No. & Items & Options \\
\hline \multirow[t]{2}{*}{ (1) } & Existence of stone signposts & Yes \\
\hline & & No \\
\hline \multirow[t]{4}{*}{ (2) } & The time of installation & 1970s \\
\hline & & $1980 \mathrm{~s}$ \\
\hline & & $1990 \mathrm{~s}$ \\
\hline & & $2000 \mathrm{~s}$ \\
\hline \multirow[t]{5}{*}{ (3) } & Creators of stone signposts & The village people \\
\hline & & Ardent lovers of village \\
\hline & & A municipal body \\
\hline & & An individual \\
\hline & & Others (school) \\
\hline \multirow[t]{17}{*}{ (4) } & Characteristics of appearance stone signposts & \\
\hline & Language & Hangeul (the Korean alphabet) \\
\hline & & Chinese characters \\
\hline & & Mixed use \\
\hline & Font & Calligraphy (Gung-suh, Hae-suh, Batang) \\
\hline & & Calligraphic modification (HY Backsoyou) \\
\hline & & Dotum or gulim \\
\hline & & Design (Hyundai Pureum) \\
\hline & Material & Natural stone \\
\hline & & Granite \\
\hline & Shape & Rectangular \\
\hline & & Oval \\
\hline & & Standing monument (native stone monument) \\
\hline & & Reclining monument (native stone, rectangle) \\
\hline & & Inverted triangle \\
\hline & & Triangle \\
\hline & & Scalene \\
\hline \multirow[t]{5}{*}{ (5) } & Discernment of stone signposts & Very bad \\
\hline & & Bad \\
\hline & & Normal \\
\hline & & Good \\
\hline & & Very good \\
\hline
\end{tabular}

Subsequently, we cross-tabulated the collected data, which involved analyzing the relationship between variables (items) by creating a contingency table to find the association between categorical variables (items). It is noted that the contingency table is a combination of rows and columns of a frequency table for each classification variable. In this study, we conducted the analysis by setting the "Time of installation" variable (item) as the descriptive variable to rows, and four items from the items 2 to 5 depicted in Table 1 as the dependent variables to columns. The causal variable (item) is called a descriptive variable, and the consequences variable is called a dependent variable.

\subsection{Main Trends of Korean Modern History Related to Rural Stone Signposts}

The cross-analysis performed on rural stone signposts clarify that the reference item "Time of installation" significantly affects other cross-setting items (four items from the items 2 to 5 shown in Table 1) to derive meaningful results. The reason is that the period of installation of rural stone signposts was constantly influenced by the main events in modern Korean history. Therefore, it is important to understand the main issues of modern Korean history during the 1970s-1980s and 1990s-2000s, when the signposts were installed. From the 1970s to the 1980s, Korea faced a worsening economic situation and domestic political turmoil following the Korean War (1950) and 4.19 Revolution (19 April 1960). At the time, the military government that newly came to power (16 May 1961) 
implemented its first five-year economic development plan (1962-1966). In addition, the economic plan was consecutively established and promoted as the economic development plan until the fourth five-year economic development plan (1976-1981) was implemented. This economic plan realized the goal of completing national reconstruction and promoting national development as a rapid economic growth process or, in other words, industrialization, to achieve economic growth through exports. However, unlike metropolitan areas, which are susceptible to rapid urbanization, rural areas tend to remain nonurbanized, which negatively affects the culture, landscape, and lifestyle of rural villages [55].

On the other hand, the military government developed a community development movement for the first time called Saemaul Undong Movement in 1970 [56]. This movement greatly contributed to the development of rural areas that had hitherto remained underdeveloped and created a change in people's consciousness. However, it was limited to the implementation of one-sided and noncommunicable government-led regional development projects that expanded the objectives and practices of the movement to the private sector through strong government-level planning and management. Consequently, since the 1990s, Korean society has been facing major social problems such as a lack of inherent landscapes and local resources in rural villages, the implementation of inconsistent development projects, and a lack of sustainable and comprehensive regional policies in rural villages [55].

The 1990s marked the completion of the Korean economic growth period and the period of centralization of metropolitan areas in terms of increases in income and urbanization perspectives. In addition, by hosting the Seoul Olympic Games in September 1988, Korea got the opportunity to open itself to the world, improve its citizens' consciousness, diversify its social culture, and so on. Subsequently, the local council was revived by the residents' autonomy system in March 1991. This phenomenon, which resulted in the improvement of citizens' consciousness, diversification of culture, and beginning of the era of citizen participation, influenced rural residents' awareness of villages and rural development policies (1985).

On the other hand, the second Saemaul Undong Movement (1988) was initiated to revamp the administration's organizational structure, including rural areas, implement aggressive practices, and find a link to civilian resource organizations. However, since the 1990s, the movement, which was widely evaluated as a Korean rural development model, has been undergoing many changes. It has spread to urban areas, been politically used, and lost its initial objectives [56]. Since the early 2000s, Korea has been undergoing decentralization and experiencing the issues posed by an aging population and population decline [55]. Despite enjoying a high level of economic growth since the 1970s, Korea is facing many community-level issues, and hence, is focusing on the problems posed by social polarization, regional underdevelopment, and the development gap between cities and rural areas. This phenomenon is witnessed in rural areas, and even rural villages, as well, and the phenomenon of hollowing out (inhabitants' abandonment of houses) is increasing in villages, which signifies the deterioration of villages. To solve this problem, in the 1990s, local communities started encouraging a sense of community in rural societies. This movement refers to the gathering of people to resolve their issues pertaining to the villages in which they live. Since the 2000s, the number of local communities in the nation has increased to 5885 , and this number continues to grow. Different types of village communities include peace eco-village, nature eco-village, village enterprise, and hope village, among others. In addition, the movement promotes projects that utilize and strengthen local characteristics such as businesses, living spaces, social welfare facilities, village environments, and landscapes by recovering the village identity, among others [55]. 


\section{Results}

\subsection{Existence of Stone Signposts}

Table 2 presents the results of the cross-analysis between the existence of a stone signpost in a rural village and its installation time. The installation time of the signpost was recorded on the outer surface of the signpost or confirmed by the residents interviewed in the field survey. Rural stone signposts were installed in $44.2 \%$ and $55.7 \%$ of villages during the 1970s-1980s and 1990s-2000s, respectively. It can be seen that stone signposts were continuously installed in rural villages from the 1970s until the late 2000s. This trend indirectly implies that such signposts are a valuable cultural asset and should be continuously preserved and managed in rural villages. From the 1970s to the 1980s, the central government initiated the Saemaul Undong Movement. During this period, a large number of standardized signposts were installed in rural villages through the Rural Development Projects movement. From the 1990s to 2000s, the local community movement, which was developed nationwide, promoted various projects, which involved gathering local residents and solving local problems by utilizing local characteristics. Therefore, during this period, residents tended to lead the installation of stone signposts in accordance with the characteristics of a local area or business.

Table 2. The relationship between the existence of stone signposts in rural villages and the time of installation.

\begin{tabular}{|c|c|c|c|c|c|c|}
\hline \multirow{2}{*}{\multicolumn{2}{|c|}{ Study Sites }} & \multicolumn{4}{|c|}{ The Time of Installation } & \multirow{2}{*}{ Total } \\
\hline & & 1970's & 1980's & 1990's & 2000's & \\
\hline \multirow{3}{*}{ Suncheon-si a } & Seo-myeon ${ }^{c}$ & 18 & 3 & 9 & 3 & 33 \\
\hline & Woldeung-myeon & 1 & 4 & 13 & 3 & 21 \\
\hline & Hwangjeon-myeon & 1 & 21 & 3 & 21 & 46 \\
\hline \multirow{3}{*}{ Boseong-gun ${ }^{b}$} & Hoecheon-myeon & 1 & 0 & 5 & 8 & 14 \\
\hline & Ungchi-myeon & 0 & 0 & 7 & 4 & 11 \\
\hline & Deungnyang-myeon & 0 & 6 & 8 & 14 & 28 \\
\hline \multirow{3}{*}{ Gokseong-gun } & Gyeom-myeon & 0 & 13 & 4 & 4 & 21 \\
\hline & Osan-myeon & 0 & 19 & 1 & 1 & 21 \\
\hline & Okgwa-myeon & 0 & 11 & 3 & 3 & 17 \\
\hline \multirow{2}{*}{ Damyang-gun } & Subuk-myeon & 2 & 3 & 5 & 5 & 15 \\
\hline & Daejeon-myeon & 1 & 4 & 5 & 7 & 17 \\
\hline \multicolumn{2}{|r|}{ Total } & $\begin{array}{c}24 \\
(9.8 \%)\end{array}$ & $\begin{array}{c}84 \\
(34.4 \%)\end{array}$ & $\begin{array}{c}63 \\
(25.8 \%)\end{array}$ & $\begin{array}{c}73 \\
(29.9 \%)\end{array}$ & $\begin{array}{c}244 \\
(100 \%)\end{array}$ \\
\hline
\end{tabular}

a,b,c In Korea, the lower administrative districts of the city and Gun (County) are Eup (Town), Myeon (Township), and Dong (Neighborhood), and the lower administrative district of Eup (Town) and Myeon (Township) is Ri (Rural Village).

\subsection{Creators of Stone Signposts}

Table 3 presents the results of a cross-analysis between the creators and times of installation of signposts. The creator of a rural stone signpost was recorded on the outer surface of the signpost or confirmed by the local residents or government agencies who were interviewed during the field survey. During the 1970s-2000s, the inhabitants of villages (45.9\%) were the most frequent creators of rural signposts. However, since the 1990s, 82 (73.3\%) of 112 villagers were found to be the creators of rural signposts. These results indicate the impact of villagers' participation on rural signpost installation during the 1990s and the performance of the community revitalization project after the 2000s; further, they imply the necessity of improving the local communities' awareness regarding their villages. Subsequently, a municipal body (33.6\%) showed the next highest frequency from the 1970 s to the 2000s. From the 1970s to 1980s, 54 (65.9\%) among the 82 municipal bodies were found to be the creators of rural signposts. Further, the government-led Saemaul Undong Movement contributed to 
the rapid increase in the number of rural signposts from the 1970s to the 1980s. During this period, the government introduced rural signposts as part of its environmental improvement projects.

Table 3. The relationship between stone signposts creator and the time of installation.

\begin{tabular}{|c|c|c|c|c|c|}
\hline \multirow{2}{*}{ Creators of Stone Signposts } & \multicolumn{4}{|c|}{ The Time of Installation } & \multirow{2}{*}{ Total } \\
\hline & 1970s & 1980s & 1990s & 2000s & \\
\hline The village people & 5 & 25 & 35 & 47 & $112(45.9 \%)$ \\
\hline Ardent lovers of village & 1 & 1 & 2 & 3 & $7(2.9 \%)$ \\
\hline A municipal body & 18 & 36 & 23 & 5 & $82(33.6 \%)$ \\
\hline An individual & 0 & 22 & 3 & 17 & $42(17.2 \%)$ \\
\hline Others (school) & 0 & 0 & 0 & 1 & $1(0.4 \%)$ \\
\hline Total & 24 & 84 & 63 & 73 & 244 \\
\hline
\end{tabular}

\subsection{Appearance Characteristics of Stone Signposts}

Table 4 depicts the results of the cross-analysis between the appearance characteristics and times of installation of signposts. Regardless of installation time, the inscription was most frequently inscribed in Hangul (85.7\%), which is the Korean alphabet (Figure 2a). From 1968 to 1972, the military regime banned the teaching of Chinese characters and demanded the use of Hangul in the Korean media to inspire national pride and the spirit of patriotism among citizens. Therefore, most of the signposts installed by the government were engraved with Korean inscriptions. However, during the 1990s and 2000s, the mixed use of Hangul and Chinese characters increased to 22 out of 27 signposts $(81.4 \%)$. During the 1988 Olympic Games, which were conducted in Seoul, the mixed use of Chinese and Korean characters was encouraged for the convenience of foreign tourists and the promotion of cultural diversity. Further, the original names of some rural villages were restored to the traditional Chinese language in order to emphasize their regional identity, which also resulted in the increased mixing of Chinese characters (Figure 2b). Regarding the use of various fonts, the basic fonts of Hangul calligraphy (Gung-suh, Hae-suh, and Batang) $(74.6 \%)$ were frequently used during the entire period of installation (Figure 2a). However, all 15 signposts using the Calligraphic modification (HYBacksoyou) font, all six signposts using the Dotum or gulim font, and 35 (85.4\%) of the 45 signposts using the Design (Hyundai Pureum) font were established between 1990-2010 (Figure 2b). Most of the fonts have been continuously developed and distributed by private companies with governmental support since the late 1980s following the Seoul Olympic Games, which has greatly influenced the country's industry, culture, and lifestyle, in general. It can be seen that the use of various fonts other than Calligraphy has increased evenly over the years.

It is noted that, regardless of installation time, stone signposts were made using a balanced combination of a natural stone (51.6\%) and a processed granite (48.4\%). During the 1970s and 1980s, $97(82.2 \%)$ of the 118 stone signposts were made of processed granite materials (Figure 2a). At the time, rural development projects demanded mass production at factories and cheap materials due to the heavy industry-centered economic growth and strong planning and management initiated by the government. Granite is a resource produced in a limited area in Korea; irrelevant mining has resulted in problems such as the degradation of natural landscapes and shortage of local resources since the 1990s. During the 1990s and 2000s, the use of natural stone materials increased to 115 (91.3\%) of 126 signposts (Figure 1b). During this period, the local community's awareness of rural villages began to increase, which is a result of the different village revitalization projects that were implemented through village community projects. In other words, it can be considered a community movement in which residents wished to make their village a sustainable one by improving the image of the village, increasing the attachment of residents, and actively attracting outsiders.

In general, the signposts are rectangular (48\%) and erect monuments (24.6\%). During the $1970 \mathrm{~s}$ and 1980s, $92(78.6 \%)$ out of 117 signposts were found to be rectangular ones. At the time of the Saemaul Movement of the government-led rural development project, the rural stone signposts were 
standardized; their sizes were made as small as possible in order to popularize them in large quantities, and their shapes were unified to a general rectangular shape (Figure 2a). During the 1990s and 2000 s, erect stones (native stone monuments) were found in 50 (83.3\%) out of 60 signposts. This high frequency can be attributed to the self-governing village projects of rural residents. In other words, there seems to be an increasing tendency to set up stone signposts by using the surrounding natural stones for the projects utilizing village characteristics, such as the improvement of village landscapes, the natural ecological village, and so on (Figure $2 b$ ).

Table 4. The relationship between appearance characteristics of stone signposts and the time of installation.

\begin{tabular}{|c|c|c|c|c|c|}
\hline \multirow{2}{*}{$\begin{array}{l}\text { Appearance Characteristics of Stone Signposts } \\
\text { Language: Use of Hangeul · Chinese Character }\end{array}$} & \multicolumn{4}{|c|}{ The Time of Installation } & \multirow{2}{*}{ Total } \\
\hline & 1970s & $1980 \mathrm{~s}$ & 1990s & $2000 s$ & \\
\hline Hangeul (the Korean alphabet) & 22 & 79 & 50 & 58 & $209(85.7 \%)$ \\
\hline Chinese characters & 1 & 1 & 4 & 2 & $8(3.3 \%)$ \\
\hline Mixed use & 1 & 4 & 9 & 13 & $27(11.1 \%)$ \\
\hline Font & 1970 s & $1980 s$ & $1990 s$ & $2000 s$ & \\
\hline Calligraphy (Gung-suh, Hae-suh, Batang) & 21 & 81 & 36 & 44 & $182(74.6 \%)$ \\
\hline Calligraphic modification (HYBacksoyou) & 0 & 0 & 6 & 9 & $15(6.1 \%)$ \\
\hline Dotum or gulim & 0 & 0 & 3 & 3 & $6(2.5 \%)$ \\
\hline Design (Hyundai Pureum) & 3 & 3 & 18 & 17 & $41(16.8 \%)$ \\
\hline Material & 1970 s & $1980 s$ & $1990 s$ & $2000 s$ & \\
\hline Natural stone & 5 & 6 & 50 & 65 & $126(51.6 \%)$ \\
\hline Granite & 19 & 78 & 13 & 8 & $118(48.4 \%)$ \\
\hline Shape & 1970 s & $1980 s$ & $1990 s$ & $2000 s$ & \\
\hline Rectangular & 17 & 75 & 14 & 11 & $117(48.0 \%)$ \\
\hline Oval & 0 & 2 & 4 & 3 & $9(3.7 \%)$ \\
\hline Standing monument (native stone monument) & 4 & 6 & 21 & 29 & $60(24.6 \%)$ \\
\hline Reclining monument (native stone, rectangle) & 2 & 1 & 10 & 7 & $20(8.2 \%)$ \\
\hline Inverted triangle & 0 & 0 & 1 & 2 & $3(1.2 \%)$ \\
\hline Triangle & 0 & 0 & 6 & 5 & $11(4.5 \%)$ \\
\hline Scalene & 1 & 0 & 7 & 16 & $24(9.8 \%)$ \\
\hline
\end{tabular}

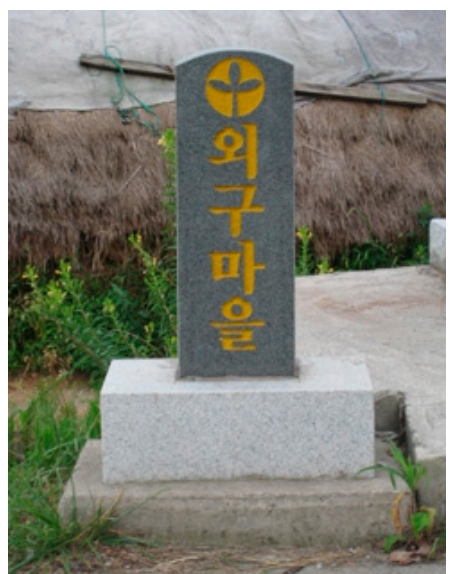

(a)

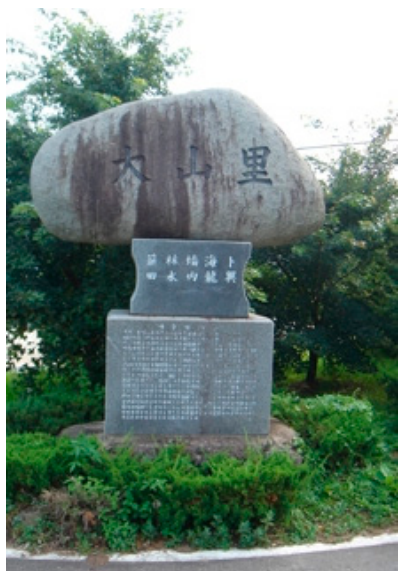

(b)

Figure 2. Example of the appearance characteristics of stone signposts: (a) Hwangjeon-myeon Yeokgu village stone signpost; (b) Ungcheon-myeon Daesan-Ri village stone signpost.

\subsection{Discernment of Stone Signposts}

Table 5 represents the results of the cross-analysis between the discovery of stone signposts in rural villages and the installation times of signposts. "Bad" and "Normal" were $75 \%$ in the 1970 s and $89.4 \%$ in the 1980 s, respectively. Evidently, the residents were unable to properly identify the signposts erected during these periods. The signposts erected during the 1970s and 1980s are often 
confused with the colors of the surrounding landscapes because of their small rectangular size and the presence of a low number of Korean fonts and inscriptions on processed granites (Figure 3a). On the other hand, "Good" and "Very good" represented $68.2 \%$ of the signposts erected during the 1990s and $84.9 \%$ that were erected in the 2000s, respectively. The signposts erected during the 1990s and 2000s were voluntarily installed by collecting the opinions of villagers and using a mixture of Korean and Chinese characters in order to preserve village traditions. On the other hand, this natural stone was also considered the type and symbolism of the erect monument, which is easy to identify (Figure 3b).

Table 5. The relationship between the identification of stone signposts and the time of installation.

\begin{tabular}{|c|c|c|c|c|c|}
\hline \multirow{2}{*}{ Discernment of Stone Signposts } & \multicolumn{4}{|c|}{ The Time of Installation } & \multirow{2}{*}{ Total } \\
\hline & 1970s & 1980s & 1990s & 2000s & \\
\hline Very bad & 2 & 3 & 1 & 0 & $6(2.5 \%)$ \\
\hline Bad & 7 & 32 & 6 & 4 & $49(20.1 \%)$ \\
\hline Normal & 11 & 43 & 13 & 7 & $74(30.3 \%)$ \\
\hline Good & 2 & 4 & 20 & 19 & $45(18.4 \%)$ \\
\hline Very good & 2 & 2 & 23 & 43 & $70(28.7 \%)$ \\
\hline
\end{tabular}

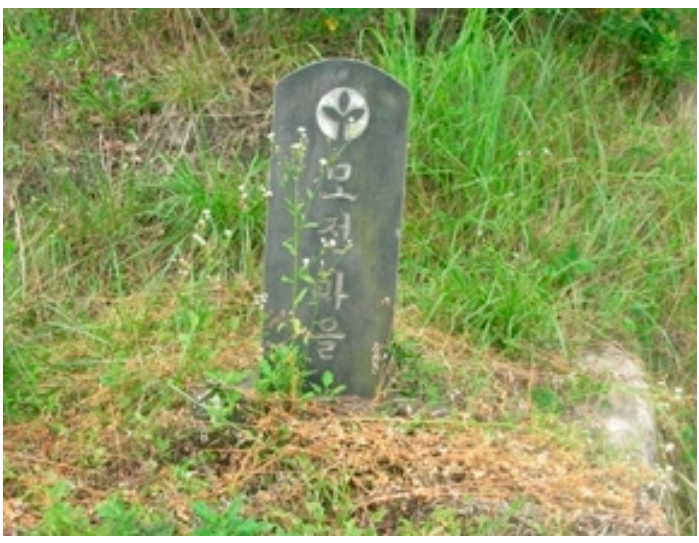

(a)

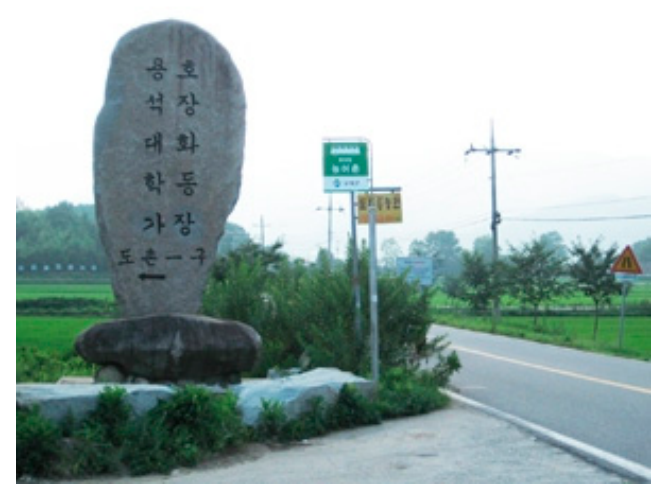

(b)

Figure 3. An example of the identification of stone signposts: (a) Hwangjeon-myeon Majeon village stone signpost; (b) Deuglyang-myeon Dochon-gu village stone signpost.

\section{Discussion}

\subsection{Physical Characteristic of the Stone Signpost in the Course of Korea's Modernization}

The purpose of this study is to analyze the physical characteristics of the stone signposts installed at the entrances of rural villages in Korea, and obtain proof that these signposts have value as elements of rural landscapes and that they should be managed sustainably as aspects of cultural heritage. The overall results of this study show that the key physical characteristics of rural stone signposts are closely correlated with the times of their installation and the major issues of modern Korean history.

From the 1970s until recently, stone signposts in rural villages were efficiently managed and steadily installed. Even though the study traces the signposts to the Korean indigenous and local knowledge that is the unique culture, values, and social institutions of the place $[57,58]$, which are represented here as Bibo Feng-shui, it is difficult to clearly analyze their characteristics of management and installation from a traditional perspective. However, it is important to sustain their existence in modern Korea. The main reason why rural stone signposts can exist sustainably is that throughout the 1970s and 1980s, the government initiated the mass production and installation of stone signposts in accordance with the objectives of the Saemaul Undong Movement, which was initiated by the central government, and since the 1990s and 2000s, the installation of stone signposts has been led by local 
communities as part of a major rural development project. Meanwhile, regarding the continuing existence of stone signposts, the characteristics of creators were that the local government led the installation during the 1970s and 1980s, and local residents have been very active creators since the 1990s and 2000s. This indicates that the common characteristic of two completely different periods is that the installation of stone signposts was affected by the influential social issues in modern Korean history, such as "government-led" and "community-led" initiatives.

The stone signposts have been identified as pivotal rural landscape elements as well. It was very important to compare and analyze the relation between the time of the installation of signposts and the modern Koreann historical trend in the appearance characteristics of stone signposts. In the initial period of installation of stone signposts (1970s-1980s), most of the language and fonts used for engraving were Hangul (the Korean alphabet) and its basic fonts (Hangul calligraphy). This was due to the unilateral policy of the military regime that prohibited the education and use of Chinese characters to infuse national patriotism. However, since the 1988 Seoul Olympic Games, the mixed use of Hangul and Chinese characters has rapidly increased in the social, living, and cultural environments of Korea. The mixed use of these languages has led to the development of various cultural content and restarted a campaign targeting the mixed use of original village names in order to restore the villages' regional identity. It was also influenced by the use of language fonts, and various fonts were developed and distributed by private companies. These phenomena led to the consideration of stone signposts as a unique regional cultural heritage element of advanced physical and rural landscapes, such as differentiating inscription fonts, restoring the identity of rural villages, and thereby enhancing outsiders' impressions of villages.

With respect to the materials used for and shapes of signposts, since they were massively produced and distributed by government-led projects during the 1970s and 1980s, most of the signposts are made of granite and have the shape of a small rectangle. On the other hand, since the stone signposts were made using a small quantity of natural stones found locally through the autonomous projects of rural villagers from the 1990s onward, the material and shape of the stone signposts were natural and various. In addition, the signposts of this period were easily distinguishable from those of the early periods, which had large volumes and a small rectangular shape, and provided additional information such as the origins of the villages and village names. Based on the characteristics of the signposts' materials and shapes, the stone signposts were recognized as being a more valuable rural landscape element during the transition in autonomy from government-led to community-led projects. It is assumed that the increasing erection of distinctive stone signposts is a result of the burgeoning of tourism from the mid-1990s onward. Public demand for the "rights to enjoy culture" was generated by economic and political forces during the late 1990s, and this led to the implementation of a local self-governing system in 1995 [59-61]. The aftermath of the economic crisis in 1997, which brought about increased demands in domestic, rather than overseas, tourism, witnessed notable demands to revise traditional rural villages as living cultural heritage. These phenomena strongly emphasized the utility of-and shed new light on - rural landscape features as prominent "symbols of a local identity" and "tourism resources" for local economies [62-65]. These changes drew attention to stone signposts as an effective medium whereby villagers could not only increase their attachment to their living place but also actively attract outsiders. The stone signposts installed by rural residents through the residents' autonomy campaign utilized an active approach of using rural landscape elements to promote the uniqueness and publicize rural villages.

Finally, the development of this approach might be attributed to the spatial and temporal boundaries demarcated by the inhabitants' local knowledge, which is based on their unique cultural traditions and religious beliefs, and the inhabitants' desire to render their living places auspicious and livable. Hence, these influences seem to convey that visible regional divisions were established through the installation of stone signposts at village entrances. Therefore, the underlying purpose of the stone signposts becomes an independent factor that plays a major role in the formation of landscapes in modern society. Conversely, the installation of signposts can be considered a tactic that is designed to 
enhance the quality of regional landscapes in rural villages and preserve their identities in modern society. This trend seems to reflect the recognition that it is necessary to have harmonious landscape features because stone signposts alone cannot fully promote a regional landscape or identity.

\subsection{For the Sustainable Conservation of the Stone Signpost}

One way to enhance quality and create more desirable landscapes that respect regionalism and local thought and reflect regional identity is to negotiate and balance the two aspects of value. The first involves regional thought that is inherited traditionally, and the second features respect for one's landscape and the harmonization of elements [66,67]. Since landscape features are artifacts formed by human culture in the natural environment, stone signposts commonly seen in Korean rural landscapes should be rediscovered and managed in terms of both tangible and intangible values. In establishing schemes for conserving and using these signposts as aspects of cultural heritage, a clear understanding of multiple values, especially intangible values based on "local knowledge", should be developed.

Local knowledge is richest when it is accumulated over generations by embedding observations and corresponding cultural adaptations within a context of long-term environmental change [68]. Similar to how stonework influenced by Bibo Feng-shui was erected at the entrance of Korean rural villages to tackle deficiencies and achieve balance and harmony between villagers' homes and natural surroundings for the prosperity of future generations, stone signposts erected from the early 1970s onward can be considered a method of managing landscapes to sustain and revive declining rural villages in the age of limitless competition. In other words, the stone signpost can be understood as a new type of the heritage asset that is material as well as immaterial, which the local community inherit, employ, transmute, add to, and transmit. Derived from complex, long-term interactions between the landscape and its sociocultural environment, signposts reveal the local knowledge of strongly embedded communities that have facilitated sustainable prosperity. In this context, the sustainability argument reinforces the view that the landscape feature witnessing evolving local knowledge should no longer be perceived in limited cultural terms-that is, only for its archaeological, architectural, or historic interest [69]. It also need not be monumental or rare to mediate between the natural and social [70]. This is why cultural landscapes in the living environment and "landscapes of the everyday" must be reevaluated and sustainably managed in order to diversify our living environment and potentially create new environments. Regarding this, the International Council on Monuments and Sites (ICOMOS) urged heritage practitioners to understand multiple values of local knowledge, along with traditional skills, in order to sustain landscape features where communities and landscape are intertwined [71]. At the foundation of this perspective, there are ideas involving "interactions between tangible and intangible aspects of place", the "rediscovery of human-nature interactions", and the "acknowledgment of cultural diversity".

In terms of cultural diversity, the important synergy between a cultural landscape and cultural diversity should be recognized by highlighting the manner in which cultural landscapes can be sustainably used to create favorable social, environmental, and economic conditions for the survival of diverse local communities [72,73]. A cultural landscape is a landscape that reflects the identity of the people living there; from this idea, we may deduce that cultural landscape features reflect cultural diversity, since they themselves are diverse [74]. This diversity enables us to perceive such landscape features as not only objects, but also resources that maintain an interdependent relationship with us. It embodies the ways in which generations of people have shaped a place with their own identities and, reciprocally, the ways in which landscape features have reinforced our values, inspired us, and reflected our sense of identity.

Another basis for the sustainable management of cultural landscapes' features, such as stone signposts, is "the involvement of local communities in passing down and utilization". This highlights the participation of local residents, which ensures that we understand the multiple values that are presented in the landscape feature' further. By actively accepting local knowledge in democratic ways, 
these values could be transmitted into conservation and management practices. This can be realized by strengthening the participation of indigenous people living in the landscape.

The local community and stakeholders, whose ways of life are determined by the surrounding landscape, which, in turn, is formed by their ways of life, must lead the management of these landscape features and learn to consolidate their own cultural landscapes through appropriate training and supervision [75-77]. Recent international trends in the management of cultural heritage, especially in the living landscapes, have moved away from an "elite approach", which tends to focus on outstanding natural phenomena. Instead, they aim to accept relative and diverse values and rely on a complex body of values to ensure the sustainable management of rural landscapes [2,78]. Here, sustainability is a sociocultural phenomenon that directly addresses the relationship between people and the world [79]. In other words, policies for managing the features of such landscapes should not be understood merely as an array of restorative and punitive processes; rather, they should have the objective of promoting the well-being of individuals and the wider expectations of a sustainable society for those individuals whose values are attached to their landscapes and landscape features, such as stone signposts. This approach is rooted in the way in which people live among their landscapes and addresses people-based issues such as the quality of life and place-based issues, including the concept of a landscape as a cadre de vie, as well as societal and social responsibilities. Certainly, similar to how landscapes cannot be created quickly, the results of landscape management cannot be obtained quickly. Since positive results require long-term effort, such management should be considered from a long-term perspective.

\section{Conclusions}

In this study, the major physical characteristics of stone signposts in Korean rural villages were compared and cross-analyzed with respect to installation time and major issues of modern Korean history. The main conclusions of the study are as follows. First, it was confirmed that stone signposts began to be installed extensively in Korean rural villages during the 1970s, which marked the beginning of economic development in Korea, and that signposts are being installed in rural areas even today. This proves that stone signposts have been constantly installed and maintained in rural areas since the early days of modern Korean history. On the other hand, since the 1990s and 2000s, the number of cases in which the residents of rural communities voluntarily installed stone signposts has increased rapidly, and in this manner, the rural stone signpost gradually became a valuable factor of visible and invisible rural landscape elements. Second, regarding the creators of rural stone signposts, the local autonomous government took the lead in founding signposts from the 1970s to 1980s; however, from the 1990s to 2000 s, the number of village residents founding the signposts was revealed to increase rapidly. This increase indicates the transformation of autonomy from government-led to resident-led efforts in the foundation of rural stone signposts. Therefore, in the future, it is necessary that the control over the sustainable installation, maintenance, and management of rural stone signposts should be handed over to the organized residents of the local rural communities. Third, according to the government-led mass production and diffusion policy, the appearance characteristics of signposts from the 1970s to 1980s were unified and included the use of Korean (alphabet), the basic typeface font, granite materials, and the shape of a small rectangle. However, due to the promotion of residents-led autonomous community promotion and activation projects in the 1990s and 2000s, the stone signposts erected in these decades had a distinctive appearance, including the mixed use of Hangul and Chinese characters, many uses of designed fonts, and the use of natural stones with various materials and sizes in rural communities. Rather than merely ensuring the diversity of appearance for unique stone signposts, residents wanted to include information and symbolism about their village, such as its history, identity, and unique publicity, in the signposts. For this purpose, residents have the potential to subvert the existence and value of stone signposts as an aspect of cultural heritage, and we need to actively support them in this effort. Fourth, whereas the rural stone signposts installed during the 1970s to 1980 s were negatively evaluated, those installed after the 1990s and 
2000s were positively evaluated. The appearance characteristics of the stone signposts influenced these evaluations, and such characteristics can be considered tactical actions for the symbolism of rural villages. Finally, when various tactical actions on the landscape elements of a rural village are continuously practiced, the heritage of the rural village is completely conserved, and the duty of the management can be established.

This study is limited to one metropolitan area (Jeollanam-do), and some of the results of the study seem to have a limitation in that they are too generalized. Therefore, this study should extend the scope of its research area to other possible regional areas in order to better clarify the characteristics and installation times of the signposts in Korean rural areas. However, in the future, it is expected that more academic value will be obtained by establishing the theory of the intrinsic significance and value of stone signposts as a rural landscape element in the rural village mentioned in this study. In addition, based on the results provided in this study, in order to improve sustainable rural landscapes, new techniques and research that evaluate and manage heritage elements such as stone signposts as valuable historical and regional aspects.

Author Contributions: The three authors contributed equally to the data analysis and writing up of the study. All authors have read and approved the final manuscript.

Acknowledgments: The constructive comments on an earlier version of this paper made by two anonymous reviewers are greatly appreciated

Conflicts of Interest: The authors declare no conflict of interest.

\section{References}

1. Plieninger, T.; Höchtl, F.; Spek, T. Traditional land-use and nature conservation in European rural landscapes. Environ. Sci. Policy 2006, 9, 317-321. [CrossRef]

2. Jung, H.J.; Ryu, J.H. Sustaining a Korean traditional rural landscape in the context of cultural landscape. Sustainability 2015, 7, 11213-11239. [CrossRef]

3. World Rural Landscape: A Worldwide Initiative for Global Conservation and Management of Rural Landscapes. Available online: http:/ / www.worldrurallandscapes.org/ (accessed on 6 April 2016).

4. Selman, P. Sustainable Landscape Planning: The Reconnection Agenda; Routledge: Oxon, UK, 2012.

5. Antrop, M. Why landscapes of the past are important for the future. Landsc. Urban Plan. 2005, 70, 21-34. [CrossRef]

6. Vanslembrouck, I.; Huylenbroeck, G. Landscape Amenities: Economic Assessment of Agricultural Landscapes; Springer: Dordrecht, The Netherlands, 2005.

7. Seong, J.I. A Study on Rural Landscape Management and Policy Directions; Korea Rural Economic Institute: Seoul, Korea, 2005.

8. Hartel, T.; Fischer, J.; Câmpeanu, C.; Milcu, A.I.; Hanspach, J.; Fazey, I. The importance of ecosystem services for rural inhabitants in a changing cultural landscape in Romania. Ecol. Soc. 2014, 19, 42. [CrossRef]

9. Stockdale, A.; Barker, A. Sustainability and the multifunctional landscape: An assessment of approaches to planning and management in the Cairngorms National Park. Land Use Policy 2009, 26, 479-492. [CrossRef]

10. Lowenthal, D. The Heritage Crusade and the Spoils of History; Cambridge University Press: Cambridge, UK, 1998.

11. Davison, G. Heritage: From Pastiche to Patrimony. In The Heritage Reader; Harrison, R., Jameson, J.H., Schofield, J., Eds.; Routledge: Abingdon, UK, 2008; pp. 31-41.

12. Peckham, R.S. Introduction: The Politics of Heritage and the Public Culture. In Rethinking Heritage: Cultures and Politics in Europe; Peckham, R.S., Ed.; I.B. Tauris \& Co.: London, UK, 2003; pp. 1-16.

13. Graham, B.; Howard, P. Heritage and Identity. In The Ashgate Research Companion to Heritage and Identity; Graham, B., Howard, P., Eds.; Routledge: London, UK, 2008; pp. 1-18.

14. Walsh, K. The Representation of the Past: Museums and Heritage in the Post Modern World; Routledge: London, UK, 1992.

15. Smith, L. Use of Heritage; Routledge: Ablingdon, UK, 2006.

16. Harvey, D.C. A History of Heritage. In The Ashgate Research Companion to Heritage and Identity; Graham, B., Howard, P., Eds.; Routledge: London, UK, 2008; pp. 19-36. 
17. Dicks, B. Heritage, Place and Community; University of Wales Press: Cardiff, UK, 2000.

18. Harrison, R. Heritage: Critical Approaches; Routledge: Oxon, UK, 2013.

19. Lowenthal, D. The Heritage Crusade and its Contradictions. In Giving Preservation a History: Histories of Historic Preservation in the United States; Page, M., Mason, R., Eds.; Routledge: London, UK, 2004; pp. $19-44$.

20. Ashworth, G.J.; Graham, B.J.; Tunbridge, J.E. Pluralising Pasts: Heritage, Identity and Place in Multicultural Societies; Pluto Press: London, UK, 2007.

21. Throsby, D. The Economics of Cultural Policy; Cambridge University Press: Cambridge, UK, 2010.

22. UNESCO. Identification and Documentation of Modern Heritage; UNESCO World Heritage Centre: Paris, France, 2003.

23. ICCROM. People-Centred Approaches to the Conservation of Cultural Heritage: Living Heritage; ICCROM: Rome, Italy, 2015.

24. Kim, K.H.; Pauleit, S. Landscape character, biodiversity and land use planning: The case of Kwangju City Region, South Korea. Land Use Policy 2007, 24, 264-274. [CrossRef]

25. Kim, K.H.; Pauleit, S. Woodland changes and their impacts on the landscape structure in South Korea, Kwangju City Region. Landsc. Res. 2009, 34, 257-277. [CrossRef]

26. Rural Resource Development Institute (RRDI). Rural Village Amenity Planning Mannual; Rural Resource Development Institute: Seoul, Korea, 2005. (In Korean)

27. Lee, M.W. Landscape Planning; Kimoondang: Seoul, Korea, 2008. (In Korean)

28. Antrop, M. The concept of traditional landscapes as a base for landscape evaluation and planning. The example of flanders region. Landsc. Urban Plan. 1997, 38, 105-117. [CrossRef]

29. Council of Europe. Explanatory Report on the Europe Landscape Convention; Council of Europe: Strabourg, France, 2000.

30. Yun, H.J.; Kim, T.H.; Shin, S.H. Entrance space planning for improving the image of rural tourism villages. J. Korean Green Tour. 2009, 16, 49-64. (In Korean)

31. Kim, D.C.; Lee, Y.S.; Lim, S.J. An interpretative study on the Nam-sa village space by shamanistic space model. J. Korean Inst. Landsc. Arch. 1999, 27, 95-107. (In Korean)

32. Shin, S.S. A study on the environmental design principles and space organization of traditional villages. J. Korean Inst. Tradit. Landsc. Arch. 2000, 18, 20-31. (In Korean)

33. Lee, K.H. Residents' recognition of house entrance at Eoeun village-The case of Eoeun. J. Korean Inst. Landsc. Arch. 2001, 29, 37-42. (In Korean)

34. Ko, S.C.; Jang, B.K. An evaluation on the cultural substantiality of the Korean traditional village-The case of Sonwon-ri in Youngchon. J. Korean Inst. Landsc. Arch. 2002, 29, 1-10. (In Korean)

35. Kim, S.J.; Jung, H.J.; Sim, W.K. Interpretation of communal spaces at traditional Korean settlement-with a special reference to Hyodong village, Yeonggwang country, Jeonnnam. J. Korean Inst. Tradit. Landsc. Arch. 2007, 25, 94-105. (In Korean)

36. Shin, J.D.; Lee, W.J.; Lee, C.S. A study on the characteristics of the locations of traditional Korean villages. J. Korea Plan. Assoc. 2008, 43, 7-25. (In Korean)

37. Shin, J.D.; Lee, W.J.; Lee, C.S. A study on the road structure of traditional Korean villages. J. Korea Plan. Assoc. 2008, 43, 91-104. (In Korean)

38. Cho, S.J.; Im, S.B.; Oh, Y.W. A study on the improvement of common facilities in the rural village. J. Korean Soc. Rural Plan. 1996, 2, 37-44. (In Korean)

39. Yun, H.J. Integrated CI planning and design for green tourism village for image distinction. J. Korean Inst. Landsc. Arch. 2006, 34, 72-79. (In Korean)

40. Kang, E.K.; Shin, Y.S.; Jee, D.N.; Kim, J.A.; Im, S.B. A study on the spatial model using participant observation. J. Korean Soc. Rural Plan. 2009, 15, 31-46. (In Korean)

41. Pratt, K.; Rutt, R. Korea: A Historical and Cultural Dictionary; Curzon: Surrey, UK, 1999.

42. Choi, C.J. Feng-Shui: Philosophy of Korea; Mineumsa: Seoul, Korea, 1984. (In Korean)

43. Kim, H.B. Village Grove Culture. In Korean Traditional Landscape Architecture; Sim, W.K., Ed.; Hollym: Seoul, Korea, 2007; pp. 425-457.

44. Min, K.H. Korean Gardens Trans; Halla Kim, Borim: Seoul, Korea, 1992.

45. Choi, C.J. The Characteristic of Korean Native Feng-Shui. In Korean Feng-Shui Culture; International Cultural Foundation, Ed.; Pagijong Press: Seoul, Korea, 2002; pp. 34-66. 
46. Han, K.T. Traditional Chinese site selection-Feng Shui: An evolutionary/ecological perspective. J. Cult. Geogr. 2001, 19, 75-96. [CrossRef]

47. Hong, S.K.; Song, I.J.; Wu, J. Fengshui theory in urban landscape planning. Urban Ecosyst. 2007, 10, $221-237$. [CrossRef]

48. Kim, D.H. Traditional Views of Nature. In Korean Historical Geography; The Association of Korean Cultural and Historical Geographers, Ed.; Purungil: Seoul, Korea, 2011; pp. 179-225. (In Korean)

49. Sim, W.K. Background of Korean Traditional Landscape Architecture. In Korean Traditional Landscape Architecture; Sim, W.K., Ed.; Hollym: Seoul, Korea, 2007; pp. 15-56.

50. Whang, B.C.; Lee, M.W. Landscape ecology planning principles in Korean Feng-Shui, Bi-Bo Woodlands and Ponds. Landsc. Ecol. Eng. 2006, 2, 147-162. [CrossRef]

51. Chang, C.R. Patterns and Practices of Village Rites. In Korean Cultural Heritage: Thought and Religion; Kim, J.W., Ed.; Korea Foundation: Seoul, Korea, 1996; pp. 166-173.

52. Jung, Y.J. Policy of cultural assets and folk beliefs in the period of Park Jung-Hee: Focused on the Guksadang and Bamseom Bugundang. Korea Soc. Hist. Folklife Stud. 2012, 39, 175-213. (In Korean)

53. Chun, M.J. Evolution and utility of Jangseung in modern stage. J. Namdo Folk 2010, 21, 243-272. (In Korean)

54. Ministry of Environment. Available online: https://egis.me.go.kr/ (accessed on 13 February 2017).

55. National Archives of Korea. Available online: http:/ / www.archives.go.kr/ (accessed on 29 May 2018).

56. Ja, J.H. People's Lives, A new discovery of Saemaul Movement and origins of historicity. Econ. Soc. 2010, 86, 360-365. (In Korean)

57. Bates, P.; Chiba, M.; Kube, S.; Nakashima, D. Learning and Knowing in Indigenous Societies Today; UNESCO: Paris, France, 2009.

58. UNESCO. Teaching and Learning for a Sustainable Future; UNESCO: Paris, France, 2010.

59. Han, S.W. Cultural Heritage Management in South Korea. Ph.D. Thesis, University of Minnesota, Minneapolis, MN, USA, 2001.

60. Yom, C.H. Korean cultural policy and cultural regulation effect: Focus on the changing 'culture' meaning since1990s. Democr. Soc. Policy Stud. 2009, 16, 212-242. (In Korean)

61. Cultural Heritage Administration: The Volume of History; Cultural Heritage Administration: Daejeon, Korea, 2011. (In Korean)

62. Kim, R.K. New evolution of cultural landscapes in cultural heritages conservation. J. Arch. Hist. 2005, 14, 288-304. (In Korean)

63. Shin, S.S. Korean Traditional Villages and Finding Cultural Landscapes; Daega Press: Seoul, Korea, 2007. (In Korean)

64. Lee, Y.Y.; Lee, J.H.; Kim, H.D.; Lee, J.K. A study on the traditional industrial landscape valued as scenic site. J. Korean Inst. Tradit. Landsc. Arch. 2012, 30, 14-27. (In Korean)

65. Ra, J.I.; Yang, S.S. The case study on the tourism resources development of rural landscape-Focusing on action plan village project at Susanri in Jeju. J. Korean Soc. Rural Plan. 2016, 22, 143-151. (In Korean) [CrossRef]

66. Phillips, A. Guidelines for Management Planning of Protected Areas; IUCN: Gland, Switzerland, 2003.

67. Laureano, P. From the Monument to the People in The International Protection of Landscapes; UNESCO: Florence, Italy, 2012.

68. Ford, J.; Martinez, D. Traditional ecological knowledge, ecosystem science, and environmental management. Ecol. Appl. 2000, 10, 1249-1250. [CrossRef]

69. Rodwell, D. Conservation and Sustainability in Historic Cities; Blackwell: Oxford, UK, 2007.

70. Jackson, J.B. Discovering the Vernacular Landscape; Yale University Press: London, UK, 1984.

71. ICOMOS. Natchitoches Declaration on Heritage Landscapes. In US/ICOMOS 7th International Symposium; ICOMOS: Natchitoches, LA, USA, 2004.

72. Soini, J.; Battaglini, E.; Birkeland, I.; Duxbury, N.; Fairclough, G.; Horlings, L.; Dessein, J. Culture in, for and as Sustainable Development: Conclusions of COST Action IS 1007 Investigating Cultural Sustainability; University of Jyväskylä: Jyväskylän yliopisto, Finland, 2015.

73. Soini, K.; Birkeland, I. Exploring the scientific discourse on cultural sustainability. Geoforum 2014, 51, $213-223$. [CrossRef]

74. Hwang, K.W. Interpreting Landscape; Seoul National University Press: Seoul, Korea, 2011. (In Korean) 
75. UNESCO Bangkok. Hoi an Protocols for Best Conservation Practice in Asia: Professional Guidelines for Assuring and Preserving the Authenticity of Heritage Sites in the Context of the Cultures of Asia; UNESCO Bangkok: Bangkok, Thailand, 2009.

76. Mason, R. Assessing Values in Conservation Planning: Methodological Issues and Choices. In Assessing the Values of Cultural Heritage; de la Torre, M., Ed.; The Getty Conservation Institute: Los Angeles, CA, USA, 2002; pp. 5-30.

77. Lisanne, G.; Pendlebury, J. Introduction: Valuing Historic Environments. In Valuing Historic Environments; Gibson, L., Pendlebury, J., Eds.; Ashgate: Farnham, UK, 2009; pp. 1-16.

78. Brown, J.; Mitchell, N.; Beresford, M. The Protected Landscape Approach: Linking Nature, Culture and Community; IUCN: Gland, Switzerland, 2005.

79. Fairclough, G. The Cultural Context of Sustainability: Heritage and Living. In Heritage and Beyond; Therond, D., Trigona, A., Eds.; Council of Europe: Paris, France, 2009; pp. 125-127.

(C) 2018 by the authors. Licensee MDPI, Basel, Switzerland. This article is an open access article distributed under the terms and conditions of the Creative Commons Attribution (CC BY) license (http://creativecommons.org/licenses/by/4.0/). 